\title{
Detailed stress fields in the focal region of the 2011 off the Pacific coast of Tohoku Earthquake-Implication for the distribution of moment release-
}

\author{
Keita Chiba, Yoshihisa Iio, and Yukitoshi Fukahata \\ Disaster Prevention Research Institute, Kyoto University, Gokasyo, Uji 611-0011, Japan \\ (Received December 28, 2011; Revised May 17, 2012; Accepted July 23, 2012; Online published January 28, 2013)
}

\begin{abstract}
We have examined the focal mechanism distributions in the source region of the 2011 off the Pacific coast of Tohoku Earthquake, before and after the mainshock, using F-net data, and then performed a stress tensor inversion by using the multiple inverse method. It is found that earthquakes were mainly reverse fault type events all over the source region before the main shock, whereas, after the main shock, many normal fault type events occurred in the hanging wall but focal mechanisms did not change in the deepest part in the source region. It is inferred from the stress tensor inversion that the stress state is a reverse fault type in the deepest part before, and after, the mainshock but that, in the central part, the stress state changed from reverse fault type before the mainshock to normal fault type after the mainshock. These results suggest that the absolute shear stress on the plate boundary fault in this region was almost completely released by the mainshock. Furthermore, we examined, in detail, the focal mechanism distributions and stress states in the shallower part near the trench axis off the Miyagi Prefecture and found that strike-slip events with the $P$-axis in the NS direction occurred in the footwall east of the mainshock hypocenter. This finding can be well explained by a slip model with a large moment release near the hypocenter. Our analysis constrains the spatial distribution of the moment release of the 2011 off the Pacific coast of Tohoku Earthquake around the mainshock hypocenter rather than in the vicinity of the trench axis.
\end{abstract}

Key words: Focal mechanism, stress inversion, multiple inverse method, fault model, seismic moment release, stress change, anelasticity, 2011 Tohoku earthquake.

\section{Introduction}

The 2011 off the Pacific coast of Tohoku Earthquake (the Tohoku earthquake) occurred at 14:46 (JST) on 11 March, 2011, along the plate boundary between the subducting Pacific plate and the overlying inland plate. It was estimated that this giant earthquake with $M_{\mathrm{w}} 9.0$ disturbed stress fields in, and around, the hypocentral region (e.g., Hasegawa et $a l ., 2011$ ). We investigated the focal mechanism distributions using the dataset obtained by the F-net over a longer time duration after the mainshock than Asano et al. (2011), and performed the stress tensor inversion by the multiple inverse method (Otsubo et al., 2008). Furthermore, we compared the spatial distributions of the focal mechanisms and stress states before, and after, the mainshock.

Numerous studies have estimated the slip distribution of the Tohoku earthquake. There are some models having a large slip in the region shallower than the mainshock hypocenter, near the trench axis off the Miyagi Prefecture (e.g., Fujii et al., 2011; Ide et al., 2011; Lay et al., 2011; Suzuki et al., 2011; Yagi and Fukahata, 2011), whereas other models have a large slip near the hypocenter of the mainshock (Ammon et al., 2011; Koketsu et al., 2011). We sought to clarify in which region the maximum moment

Copyright (C) The Society of Geomagnetism and Earth, Planetary and Space Sciences (SGEPSS); The Seismological Society of Japan; The Volcanological Society of Japan; The Geodetic Society of Japan; The Japanese Society for Planetary Sciences; TERRAPUB.

doi:10.5047/eps.2012.07.008 release by the mainshock occurred, by comparing the above observations with stress changes calculated from typical models with a different moment release distribution.

In stress tensor inversion, we usually divide a model region into a finite number of grids and specify a stress state for each grid. If we try to estimate a detailed spatial distribution of stress states from a dataset with large hypocentral errors, however, it can be difficult to properly set grids for the inversion, owing to the hypocentral errors. In this study, we use the F-net data that possibly include hypocentral errors, particularly near the trench region. We then used a multiple inverse method and K-means clustering (Otsubo et al., 2006), which can give plural stress states within one grid. By this method, we can more precisely evaluate the stress states from a dataset with large hypocentral errors.

\section{Data and Focal Mechanism Distribution}

We used 4091 focal mechanisms estimated from F-net data from January 1, 1997, to September 27, 2011 (2358 events before the mainshock and 1733 events after the mainshock) with variance reductions better than $60 \%$. We plotted the $P$-axes before and after the mainshock in Fig. 1, which were classified by the plunges of $P, T$, and null axes, following Frohlich (1992). Before the mainshock, focal mechanisms were predominantly reverse faulting except for the events in the outer rise, and the azimuth of $P$-axes were almost consistent with the plate convergence direction (WNW-ESE). On the other hand, as shown in Asano et al. 
$19971 / 1-20113 / 11$

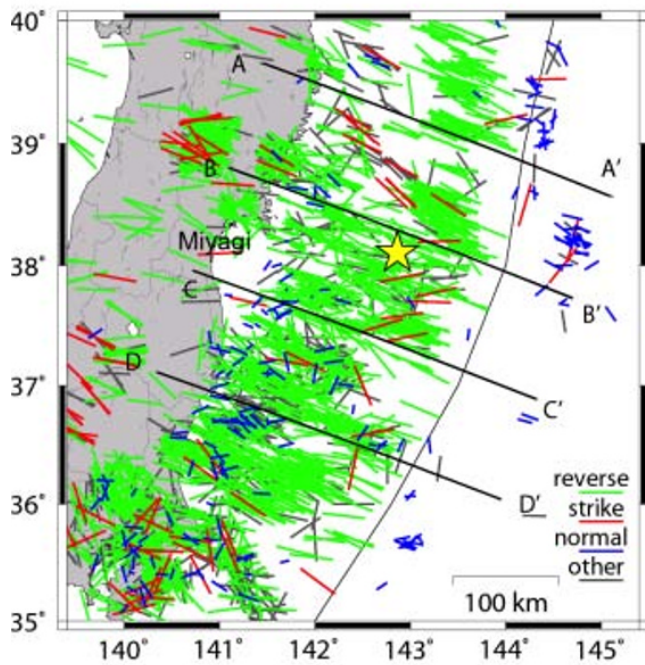

$20113 / 11-20119 / 27$

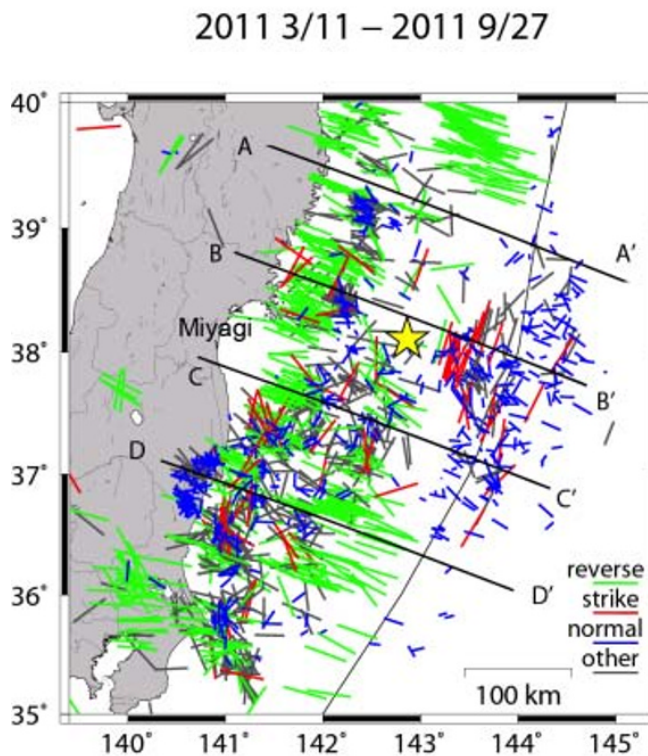

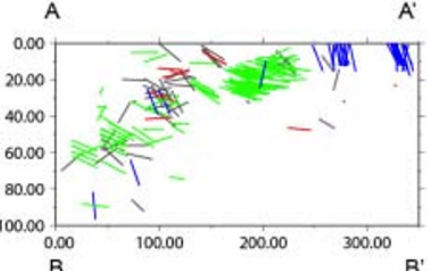
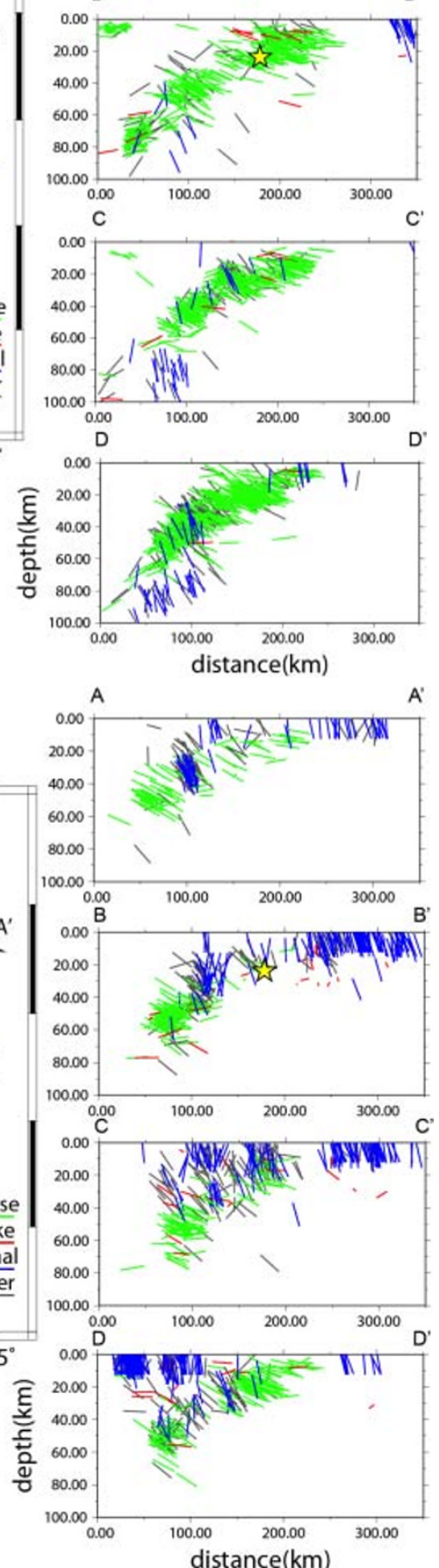

Fig. 1. $P$-axis distributions projected on the horizontal and vertical sections before, and after, the mainshock in the upper and lower panels, respectively Green, red, blue and grey bars represent reverse, strike, normal and other types, based on Frohlich (1992), respectively. In the Frohlich (1992) scheme, reverse faults have a $T$-axis plunge greater than 50 degrees, strike-slip faults a $B$-axis greater than 60 degrees, normal faults a $P$-axis greater than 60 degrees. The star represents the hypocenter of the mainshock by the Japan Meteorological Agency (JMA).

(2011), a number of normal fault type events occurred after the mainshock, especially in the hanging wall and in the outer rise. Reverse fault type events did not occur around the plate interface in the shallower part, from the hypocenter of the mainshock to the trench axis. These results suggest that a tensional stress change due to the mainshock was generated over a wide area; in particular, in the hanging wall of the shallower part and in the outer rise. On the other hand, 
$20113 / 11-20119 / 27$
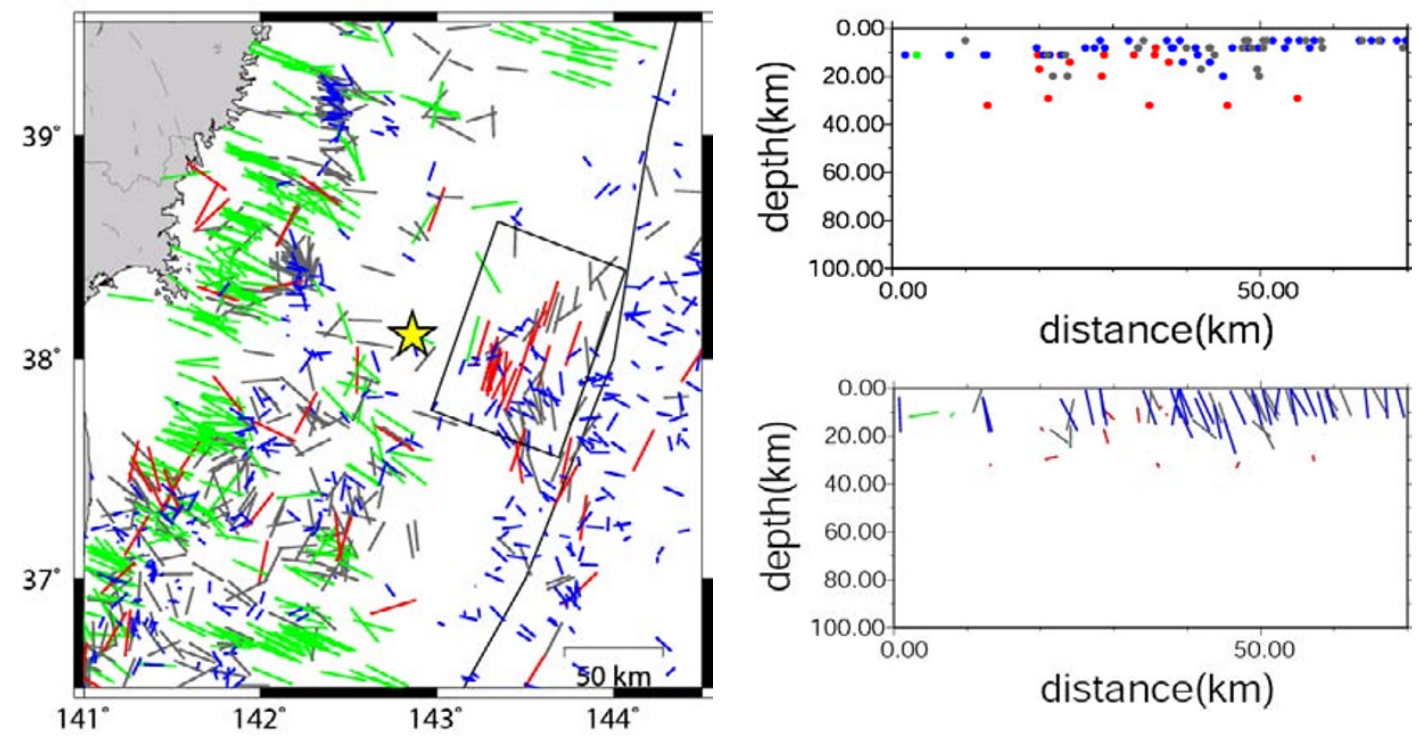

Fig. 2. (Left) $P$-axis distributions near the trench axis. The data enclosed by the rectangle in the left panel are shown in the right two panels: (Right top) hypocentral distribution projected on the vertical cross-section and (right bottom) $P$-axis distribution projected on the vertical cross-section. Colors are used in the same manner as in Fig. 1. The star represents the hypocenter of the mainshock by the Japan Meteorological Agency (JMA).

in the deepest part of the focal region, where reverse fault type events were still observed after the mainshock, it is estimated that stress releases are smaller than the absolute stress on and/or near the earthquake fault. However, a compressional stress change might occur around the edge of the earthquake fault.

The focal mechanism distributions near the trench axis off the Miyagi Prefecture is particularly interesting. Figure 2 represents the horizontal and vertical crosssections of the $P$-axes there. It appears that many strikeslip events with the $P$-axes in the NS direction occurred in the footwall mainly in the left side of the region shown in Fig. 2.

The moment tensor analysis, in which the F-net focal mechanism data are determined, utilizes the unified hypocenter catalogue (Japan Meteorological Agency, 1998). In the catalogue, errors in epicenter and focal depth are smaller than about 0.1 degree and $10 \mathrm{~km}$, respectively (Japan Meteorological Agency, 1998). According to the F-net web-site (NIED, www.fnet.bosai.go.jp.), errors in hypocentral location in the moment tensor analysis are equal or smaller than those in the unified hypocenter catalogue, hence, the errors in epicenter and focal depth are smaller than $9 \mathrm{~km}$ and $10 \mathrm{~km}$, respectively. Thus, it is likely that those strike-slip events occurred in the footwall mainly in the left side of the region in Fig. 2, although there are errors in the epicenter and focal depth. As discussed later, these events suggest that the maximum seismic moment release by the mainshock did not occur in the shallowest part near the trench axis, but rather near the mainshock hypocenter.

\section{Stress Tensor Inversion}

In the stress tensor inversion, we used the multiple inverse method (Yamaji, 2000; Otsubo et al., 2008), which uses a resampling technique to separate spatiotemporal plural stress states. This method resamples data to produce $K_{f^{-}}$ element subsets from a total of $N$ events, and the number of $K_{f}$-element subsets is given by the binomial coefficient ${ }_{2 N} \mathrm{C}_{K_{f}}$, where $2 N$ represents that each event has an auxiliary fault plane, and $K_{f}$ is taken to be 4 or 5 , since the number of unknown parameters is four. After two-step screenings, an optimal stress state, based on the Wallace-Bott hypothesis (Wallace, 1951; Bott, 1959) that an earthquake slip's vector is parallel to the resolved shear stress on the fault plane, is calculated by the least-squares method which minimizes the difference between the calculated and observed slip directions for each subset (Gephart and Forsyth, 1984; Michael, 1987). The difference in the stress states is quantitatively evaluated by the angular stress distance on a unit sphere in a five-dimensional Euclidean space (Sato and Yamaji, 2006). The angular stress distance, which ranges from 0 to 180 degrees, is defined by the angular distance along the great circle of the five-dimensional unit sphere. A stress state for each $K_{f}$-element subset is plotted by a point on the five-dimensional unit sphere, and predominant stress states are recognized as clusters of points on the fivedimensional sphere. When there are plural stress states, we use the method of K-means clustering to separate the stress states (Otsubo et al., 2006).

In this study, we divided the model region as shown in Fig. 3. Although we basically considered that the plate interface in these subregions was fully ruptured by the mainshock, the coseismic slip possibly did not reach the western end of the deepest subregions; in particular, in subregion 1. If this is the case, we should be careful in interpreting the stress state in the subregions, since stress concentrations can be generated at the edge of the earthquake fault. We performed the stress tensor inversion only for the regions with more than 20 focal mechanisms. The results are shown in 

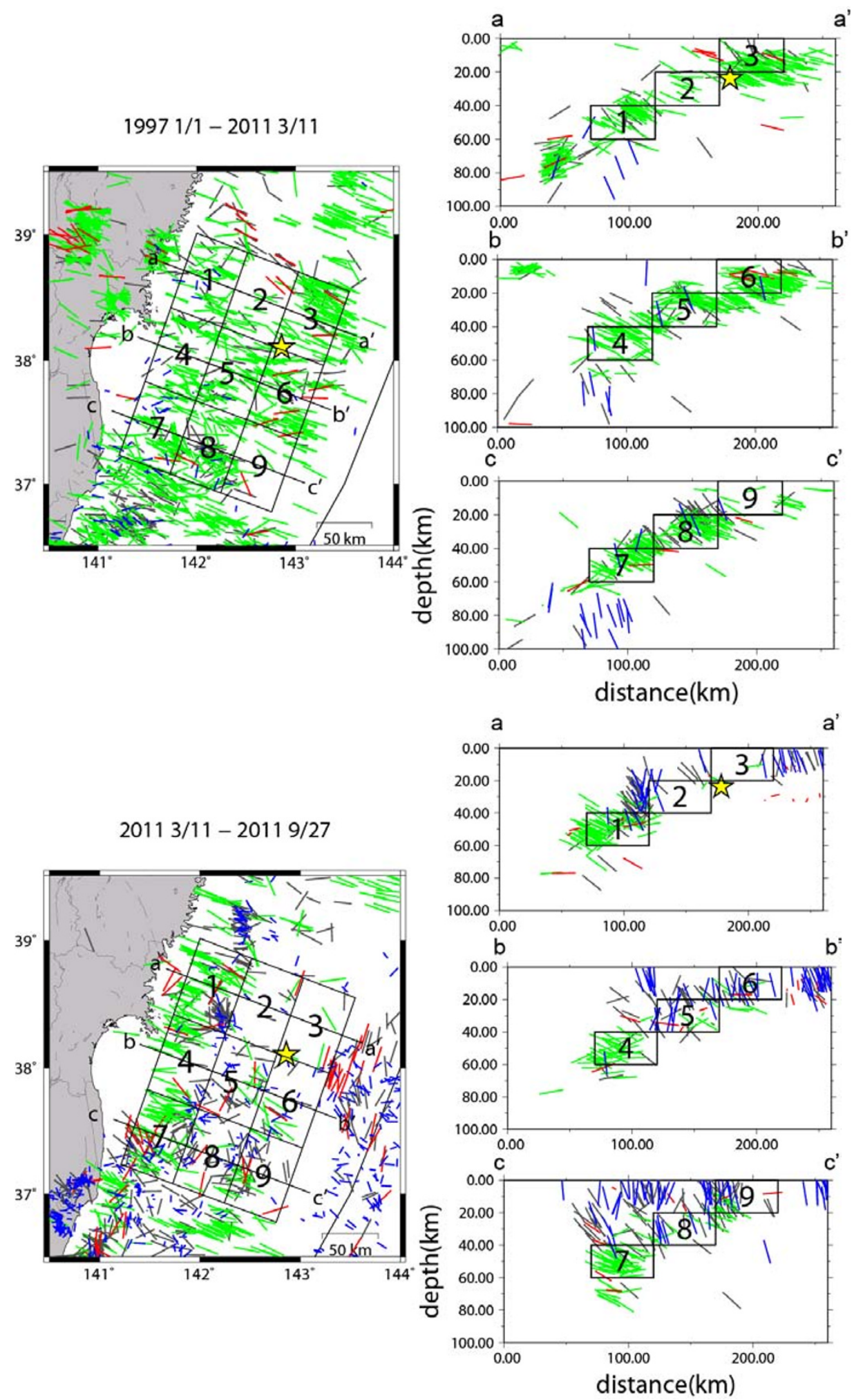

Fig. 3. Location of the grids for the stress tensor inversion (Fig. 4) except for near the trench axis. The lengths of the grids are 50 and $70 \mathrm{~km}$, perpendicular and parallel to the trench axis, respectively, and $20 \mathrm{~km}$ in the vertical direction. The star represents the hypocenter of the main shock determined by JMA.

Fig. 4 and Tables 1 and 2. The left- and right-hand sides of Fig. 4 represent the maximum and minimum principal stresses for before, and after, the mainshock, respectively. Each point in the lower hemisphere represents a solution for each subset calculated by the multiple inverse method. The stress ratio defined as $\varphi=\left(\sigma_{2}-\sigma_{3}\right) /\left(\sigma_{1}-\sigma_{3}\right)$ is rep- resented by a color.

The results of the stress tensor inversion show that in the central and shallower parts of the focal region-subregions 5, 6, and 8-the stress state drastically changed from the thrust type to the normal fault type after the mainshock. On the other hand, the stress state in the deepest part of 

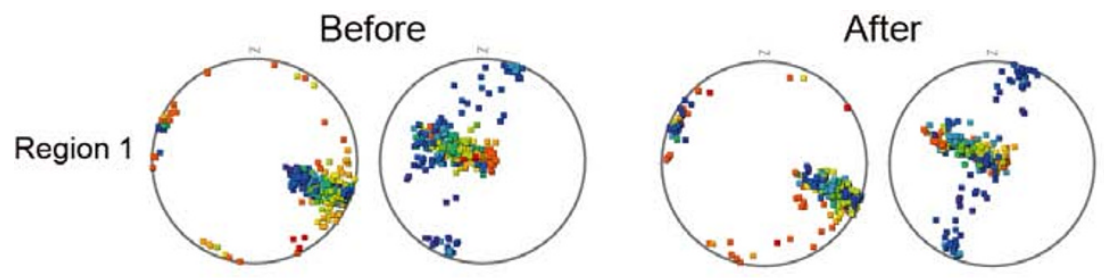

Region 2
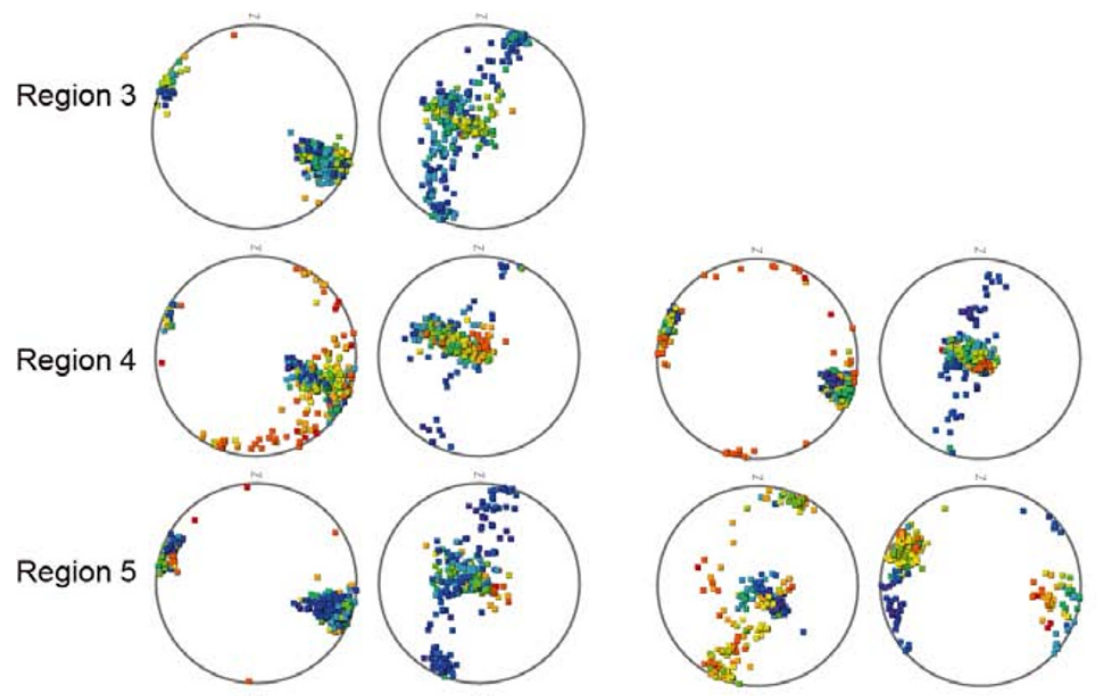

\section{Stress ratio}
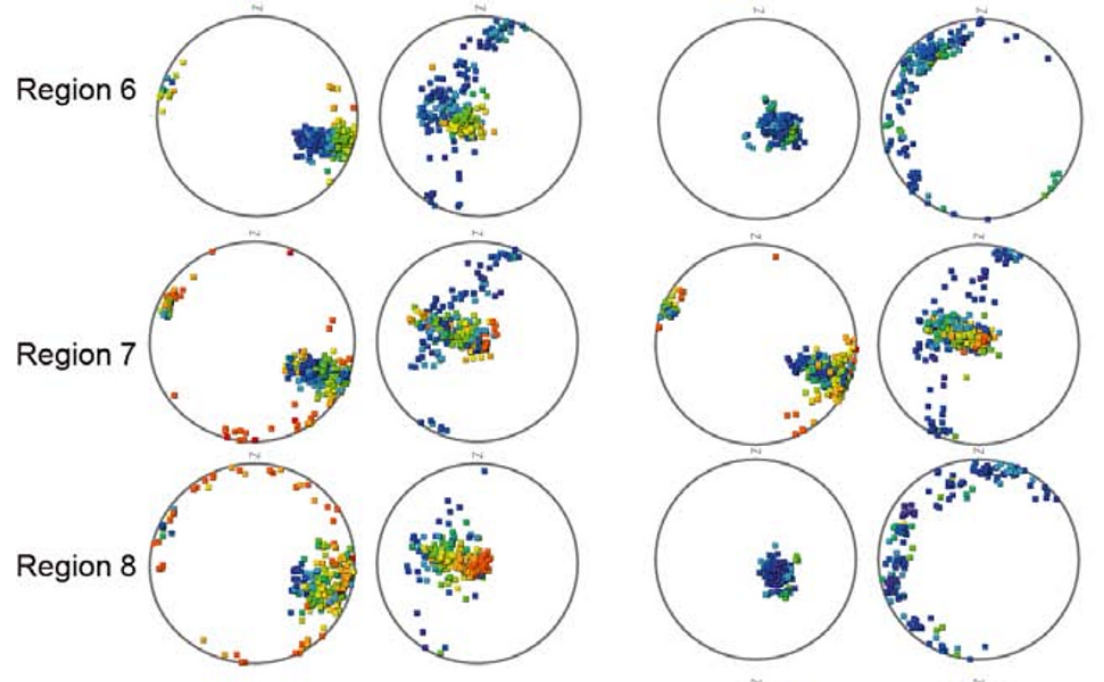

Region 9

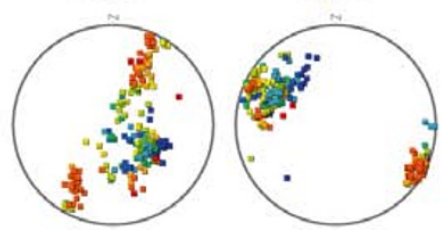

Fig. 4. Results of stress tensor inversion by the multiple inverse method. Solutions are plotted on the lower hemisphere. Left and right panels represent the maximum and minimum principal stresses, respectively. The stress ratio $\varphi$ is defined as $\varphi=\left(\sigma_{2}-\sigma_{3}\right) /\left(\sigma_{1}-\sigma_{3}\right)$ and represented by color. Red and blue show $\varphi=1$ and $\varphi=0$, respectively. In the blank regions, stress tensor inversion was not performed because of less than 20 focal mechanisms.

the focal region-subregions 1,4 , and 7-remains as the reverse fault type even after the mainshock. Hasegawa et al. (2011) also estimated from $\sigma_{1}$-axis rotations determined by their stress tensor inversion that the ratio of the mainshock stress drop to the background deviatoric stress $\Delta \tau / \tau$ is about $0.90-0.95$. The drastic change in the stress state in the central and shallower parts therefore implies that the absolute shear stress on the plate-boundary fault in this region was almost completely released by the mainshock (Hasegawa et al., 2011; Yagi and Fukahata, 2011).

We also performed the stress tensor inversion for the region from the mainshock hypocenter to the trench axis shown in Fig. 2. As mentioned above, strike-slip events occurred mainly in the left half of this region. Furthermore, it 
Table 1. Results of stress tensor inversion before the mainshock (left columns of Fig. 4). The stress ratio $\varphi$ is defined as $\varphi=\left(\sigma_{2}-\sigma_{3}\right) /\left(\sigma_{1}-\sigma_{3}\right)$ The stress difference $D$ is related to the angular stress distance $\omega$ on a five-dimensional unit sphere as $(D / 2)=\sin (\omega / 2)($ Sato and Yamaji, 2006). $D$ ranges from 0 to 2 . $D=0$ and 2 mean the identical and opposite stress states, respectively. $\bar{D}$ and $\bar{\omega}$ represent the mean stress difference and mean angular stress distance from an optimal solution, respectively. Stress tensor inversion was performed only for those regions with more than 20 focal mechanisms.

\begin{tabular}{|c|c|c|c|c|c|c|c|c|}
\hline & $\begin{array}{c}\sigma_{1} \text { azi } \\
\text { (degree) }\end{array}$ & $\begin{array}{c}\sigma_{1} \text { dip } \\
\text { (degree) }\end{array}$ & $\begin{array}{c}\sigma_{3} \text { azi } \\
\text { (degree) }\end{array}$ & $\begin{array}{c}\sigma_{3} \text { dip } \\
\text { (degree) }\end{array}$ & $\varphi$ & $\bar{D}$ & $\begin{array}{c}\bar{\omega} \\
\text { (degree) }\end{array}$ & $\begin{array}{c}N \\
\text { (event number) }\end{array}$ \\
\hline Region 1 & $111.7^{\circ}$ & $25.0^{\circ}$ & $296.0^{\circ}$ & $65.0^{\circ}$ & 0.40 & 0.649 & $38.363^{\circ}$ & 43 \\
\hline Region 2 & & & & & & & & 10 \\
\hline Region 3 & $115.8^{\circ}$ & $20.8^{\circ}$ & $274.6^{\circ}$ & $67.9^{\circ}$ & 0.15 & 0.575 & $33.668^{\circ}$ & 48 \\
\hline Region 4 & $112.5^{\circ}$ & $23.0^{\circ}$ & $303.2^{\circ}$ & $66.7^{\circ}$ & 0.58 & 0.625 & $36.868^{\circ}$ & 44 \\
\hline Region 5 & $109.5^{\circ}$ & $15.1^{\circ}$ & $295.0^{\circ}$ & $74.9^{\circ}$ & 0.19 & 0.561 & $32.959^{\circ}$ & 67 \\
\hline Region 6 & $109.6^{\circ}$ & $23.6^{\circ}$ & $278.9^{\circ}$ & $66.0^{\circ}$ & 0.23 & 0.575 & $33.629^{\circ}$ & 63 \\
\hline Region 7 & $115.2^{\circ}$ & $19.4^{\circ}$ & $301.5^{\circ}$ & $70.5^{\circ}$ & 0.41 & 0.631 & $37.198^{\circ}$ & 43 \\
\hline Region 8 & $108.6^{\circ}$ & $21.3^{\circ}$ & $283.6^{\circ}$ & $68.6^{\circ}$ & 0.61 & 0.601 & $35.426^{\circ}$ & 75 \\
\hline Region 9 & & & & & & & & 6 \\
\hline
\end{tabular}

Table 2. Results of stress tensor inversion after the mainshock (right columns of Fig. 4).

\begin{tabular}{|c|c|c|c|c|c|c|c|c|}
\hline & $\begin{array}{c}\sigma_{1} \text { azi } \\
(\text { degree })\end{array}$ & $\begin{array}{c}\sigma_{1} \text { dip } \\
\text { (degree) }\end{array}$ & $\begin{array}{c}\sigma_{3} \text { azi } \\
\text { (degree) }\end{array}$ & $\begin{array}{c}\sigma_{3} \text { dip } \\
\text { (degree) }\end{array}$ & $\varphi$ & $\bar{D}$ & $\begin{array}{c}\bar{\omega} \\
\text { (degree) }\end{array}$ & $\begin{array}{c}N \\
\text { (event number) }\end{array}$ \\
\hline Region 1 & $112.4^{\circ}$ & $18.3^{\circ}$ & $308.0^{\circ}$ & $71.1^{\circ}$ & 0.36 & 0.656 & $38.793^{\circ}$ & 70 \\
\hline Region 2 & & & & & & & & 7 \\
\hline Region 3 & & & & & & & & 5 \\
\hline Region 4 & $108.3^{\circ}$ & $7.9^{\circ}$ & $282.6^{\circ}$ & $82.1^{\circ}$ & 0.46 & 0.474 & $27.524^{\circ}$ & 33 \\
\hline Region 5 & $184.9^{\circ}$ & $62.6^{\circ}$ & $292.4^{\circ}$ & $8.9^{\circ}$ & 0.75 & 0.700 & $41.576^{\circ}$ & 26 \\
\hline Region 6 & $112.2^{\circ}$ & $71.9^{\circ}$ & $316.3^{\circ}$ & $16.6^{\circ}$ & 0.17 & 0.356 & $20.570^{\circ}$ & 24 \\
\hline Region 7 & $111.9^{\circ}$ & $19.7^{\circ}$ & $300.7^{\circ}$ & $70.1^{\circ}$ & 0.39 & 0.568 & $33.285^{\circ}$ & 46 \\
\hline Region 8 & $124.4^{\circ}$ & $69.5^{\circ}$ & $242.6^{\circ}$ & $10.0^{\circ}$ & 0.03 & 0.314 & $18.149^{\circ}$ & 20 \\
\hline Region 9 & $126.6^{\circ}$ & $70.9^{\circ}$ & $295.0^{\circ}$ & $18.7^{\circ}$ & 0.69 & 0.695 & $40.879^{\circ}$ & 39 \\
\hline
\end{tabular}

\#data
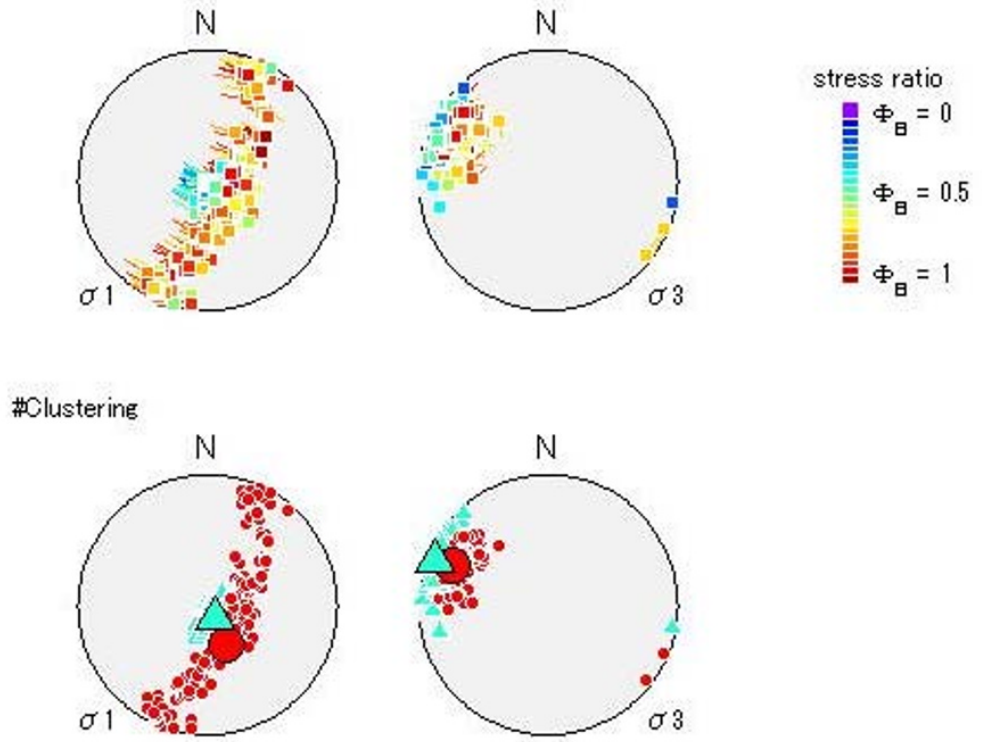

Fig. 5. Results of stress tensor inversion (top) and K-means clustering (bottom) in the shallower part near the trench axis shown in Fig. 2. The top panel is obtained in the same way as in Fig. 4. In K-means clustering, we assumed two clusters for stress states. The large circle and triangle show the two representative stress states.

is inferred from the depth distribution shown in Fig. 2, and the errors in the hypocenter location, that these strike-slip events are located in the footwall. On the other hand, normal fault events mainly occur in the upper part of the region. The result of the stress tensor inversion, shown in the upper panel of Fig. 5, implies the existence of two stress states in this region; one is the normal fault type with a small stress ratio and the other is the normal fault to strike-slip fault type with a large stress ratio. The latter cluster corresponds to the occurrence of the strike-slip events shown in Fig. 2. 
Table 3. Results of stress tensor inversion shown in the top panel of Fig. 5 (upper) and K-means clustering shown in the bottom panel of Fig. 5 (lower).

\begin{tabular}{|c|c|c|c|c|c|c|c|c|}
\hline & $\begin{array}{c}\sigma_{1} \text { azi } \\
\text { (degree) }\end{array}$ & $\begin{array}{c}\sigma_{1} \text { dip } \\
\text { (degree) }\end{array}$ & $\begin{array}{c}\sigma_{3} \text { azi } \\
\text { (degree) }\end{array}$ & $\begin{array}{c}\sigma_{3} \operatorname{dip} \\
(\text { degree })\end{array}$ & $\varphi$ & $\bar{D}$ & $\begin{array}{c}\bar{\omega} \\
(\text { degree })\end{array}$ & $\begin{array}{c}N \\
\text { (event number) }\end{array}$ \\
\hline \multirow[t]{5}{*}{ average } & $140.8^{\circ}$ & $71.1^{\circ}$ & $292.6^{\circ}$ & $16.8^{\circ}$ & 0.79 & 0.474 & $27.525^{\circ}$ & 78 \\
\hline & \multicolumn{8}{|c|}{ Results of K-means clustering } \\
\hline & & $\begin{array}{c}\sigma_{1} \text { azi } \\
\text { (degree) }\end{array}$ & $\begin{array}{c}\sigma_{1} \text { dip } \\
\text { (degree) }\end{array}$ & $\begin{array}{c}\sigma_{3} \text { azi } \\
\text { (degree) }\end{array}$ & $\begin{array}{c}\sigma_{3} \operatorname{dip} \\
(\text { degree })\end{array}$ & $\varphi$ & $\bar{D}$ & $\begin{array}{c}\bar{\omega} \\
(\text { degree })\end{array}$ \\
\hline & Clus 1 & $155.84^{\circ}$ & $62.43^{\circ}$ & $292.70^{\circ}$ & $20.85^{\circ}$ & 0.94 & 0.46 & $26.88^{\circ}$ \\
\hline & Clus 2 & $152.87^{\circ}$ & $80.55^{\circ}$ & $290.71^{\circ}$ & $7.03^{\circ}$ & 0.39 & 0.22 & $12.87^{\circ}$ \\
\hline
\end{tabular}
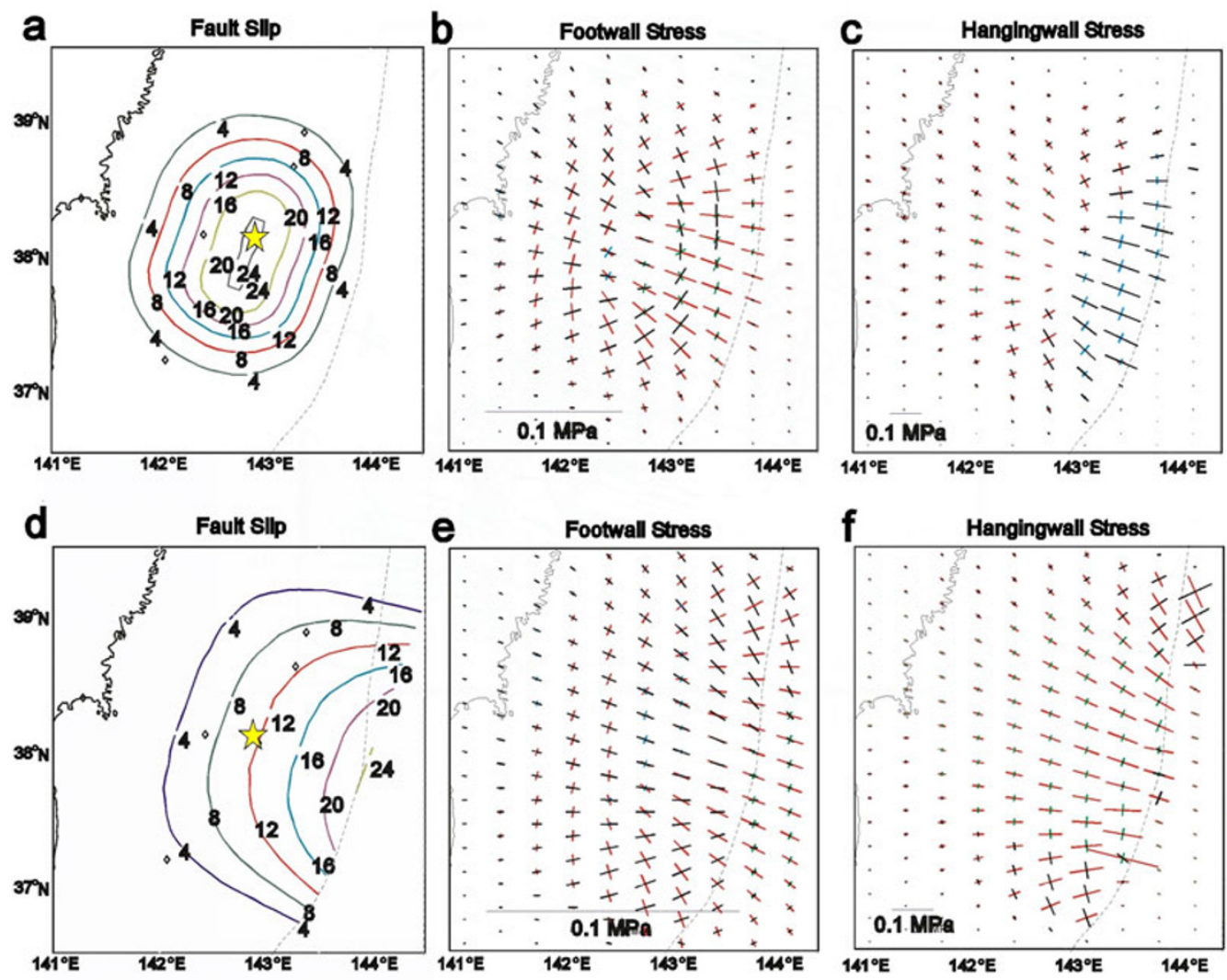

Fig. 6. (a) and (d): Slip models with the large moment release near the hypocenter and the trench axis, respectively. Numerals attached to the contour lines represent the slip amount in meters. (b) and (e): Stress changes represented as directions and magnitudes of deviatoric principal stresses projected on the horizontal plane in the footwall at a depth of $10 \mathrm{~km}$ under the plate boundary. (c) and (f): Stress changes in the hanging wall at the depth of 1 $\mathrm{km}$ below the surface. The stress changes shown in (b) and (c) and (e) and (f) are calculated from the slip models of (a) and (d), respectively. Black and red represent the maximum and mimimum deviatoric principal stresses, respectively. Blue and green represent the medium deviatoric principal stress in the compressional and tensile direction, respectively.

These results suggest that the stress state in the left half of the region is probably a strike slip type in the footwall.

In order to confirm more definitely the stress states, we tried to separate these two stress states using the K-means clustering method (Otsubo et al., 2006). As shown in the lower panel of Fig. 5, it is seen that a cluster representing the stress state of the strike-slip to normal fault type shown by red was distinguished from that of the normal fault type shown by blue. Although the two stress states are very similar in the $P$ - and $T$-axes, the stress ratio is completely different. The two stress states are separated by $42.4^{\circ}$ in angular stress distance. The mean angular stress distance that expresses the average spread within a cluster is $26.88^{\circ}$ and $12.87^{\circ}$ for each cluster, respectively. Since the angular stress distance between the two clusters is larger than the sum of the average spreads of these clusters, it is likely that the two stress states are distinguished. The method of $\mathrm{K}$ means clustering is suitable for data with large hypocentral errors, to obtain stress fields in detail.

\section{Discussion}

In order to understand the stress state of the strike-slip type with the $P$-axis in the NS direction, which was estimated in the footwall in the western part of the shallower region near the trench axis shown in Fig. 2, we have calculated the stress changes predicted by the two end members 
of the slip models shown in Figs. 6(a) and 6(d), using Okada (1992). Here, we set the two-dimensional fault model approximately along the plate boundary by Hasegawa et al. (1994). The model fault consists of flat subfaults with a length of $10 \mathrm{~km}$ both in the strike and dip directions and the slip amount within each subfault is uniform. We then compared the calculated stress changes with the observed $P$-axis distribution shown in Fig. 2.

Figures 6(a) and 6(d) show the slip distribution models with large slip around the mainshock hypocenter and near the trench axis, respectively. Figures 6(b) and (c), and 6(e) and (f), show the stress changes calculated from the slip distribution of Figs. 6(a) and (d), respectively. Since an elastic half-space with constant elastic properties is assumed in this calculation, the slip distributions of Figs. 6(a) and 6(d) correspond to the distributions of seismic moment release. Figures 6(b) and (e) represent the stress changes at a depth of $10 \mathrm{~km}$ beneath the plate boundary, namely in the footwall, and Figs. 6(c) and (f) represent those at the depth of $1 \mathrm{~km}$ from the surface, namely in the hanging wall. These stress changes are represented as directions and magnitudes of deviatoric principal stresses, projected onto the horizontal plane. It is found in Fig. 6(b) that $\sigma_{1}$-axes trending in the NS direction are distributed to the east of a large seismic moment release shown in Fig. 6(a), where the $P$-axes in the NS direction are distributed in the same horizontal location (Fig. 2). On the other hand, if we assume a large moment release near the trench axis, $\sigma_{1}$-axes trending in the NS direction are not seen around the same location both in the footwall (Fig. 6(e)) and in the hanging wall (Fig. 6(f)). These results suggest that the Tohoku earthquake has the maximum moment release near the hypocenter as shown in Fig. 6(a), not near the trench axis, as shown in Fig. 6(d).

Large surface displacements up to $24 \mathrm{~m}$, however, were observed by the GPS/acoustic seafloor geodetic observations (Sato et al., 2011). In addition to this, the fault models estimated from tsunami data also indicate a large slip near the trench axis (e.g., Fujii et al., 2011). These observations can be explained by a small rigidity in the hanging wall near the trench axis. Since Figs. 6(a) and 6(d) are regarded as the moment release distributions, if the actual rigidity is small in the hanging wall near the trench axis, as shown in Fig. 6(a), large surface displacements are generated in spite of a relatively small moment release. Actually, it is difficult to estimate the true slip distribution on the fault plane under situations with heterogeneous elastic properties. However, slips near the trench axis could also be larger than those shown in Fig. 6(a). This point is demonstrated by Lay et al. (2011), who compared slip and moment release distributions, assuming 1-D elastic structure. Since our estimation of the moment release distribution is based on the focal mechanism distributions in the footwall, where elastic properties are homogeneous, rather than in the hanging wall, it is likely that the moment release have a peak near the mainshock hypocenter. Furthermore, displacements can be amplified by anelastic effects in the hanging wall near the trench axis. In fact, a lot of tensile cracks have been observed at the ocean bottom near the trench (e.g. Tsuji et al., 2011), which represents the occurrence of anelastic deformation, at least near the Earth's surface.

\section{Conclusion}

We examined the focal mechanism distributions before and after the Tohoku earthquake and performed a stress tensor inversion using a multiple inverse method (Otsubo et al., 2008). We confirmed that most of the earthquakes which occurred before the mainshock were reverse fault type events and the $P$-axes of these focal mechanisms were directed in the plate convergence direction (NWN-ESE), but that most of earthquakes in the hanging wall after the mainshock are normal fault type ones, as already pointed out by Asano et al. (2011). On the other hand, we found that focal mechanism types did not change in the deepest part in the focal region before and after the mainshock.

It was inferred from the stress tensor inversion that the stress state is a reverse fault type in the deepest part in the focal region before and after the mainshock, but, in the central part, the stress state changed from reverse fault type before the mainshock to normal fault type after the mainshock. In this way, we succeeded in estimating the depthdependent stress states after the mainshock. These results imply that the absolute shear stress on the plate boundary fault in this region was almost completely released by the mainshock (Hasegawa et al., 2011; Yagi and Fukahata, 2011).

Furthermore, we examined in detail the focal mechanism distributions and stress states in the shallower part near the trench axis off the Miyagi Prefecture and found that the model with the large moment release near the hypocenter well explains that the strike-slip events with the $P$-axis in the NS direction occurred in the footwall, east of the mainshock hypocenter. Thus, our analysis constrains the spatial distribution of the moment release of the Tohoku earthquake around the mainshock hypocenter rather than in the vicinity of the trench axis.

Acknowledgments. In this study, we used a focal mechanisms determined by the F-net of the National Research Institute for Earth Science and Disaster Prevention (NIED). We also used the multiple inverse method (Sato and Yamaji, 2006; Yamaji and Sato, 2006; Otsubo et al., 2008) and K-means clustering (Otsubo et al., 2008). We thank Akira Hasegawa and two anonymous reviewers for the improvement of the manuscript The figures are prepared using GMT (Wessel and Smith, 1995).

\section{References}

Ammon, C. J., T. Lay, H. Kanamori, and M. Cleveland, A rupture model of the 2011 off the Pacific coast of Tohoku Earthquake, Earth Planets Space, 63, 693-696, 2011.

Asano, Y., T. Saito, Y. Ito, K. Shiomi, H. Hirose, T. Matsumoto, S. Aoi, S. Hori, and S. Sekiguchi, Spatial distribution and focal mechanisms of aftershocks of the 2011 off the Pacific coast of Tohoku Earthquake, Earth Planets Space, 63, 669-673, 2011.

Bott, M. H. P., The mechanics of oblique slip faulting, Geol. Mag., 96, 109-117, 1959.

Frohlich, C., Triangle diagrams: Ternary graphs to display similarity and diversity of earthquake focal mechanisms, Phys. Earth Planet. Inter., 75, 193-198, 1992.

Fujii, Y., K. Satake, S. Sakai, M. Shinohara, and T. Kanazawa, Tsunami source of the 2011 off the Pacific coast of Tohoku Earthquake, Earth Planets Space, 63, 815-820, 2011.

Gephart, J. W. and D. W. Forsyth, An improved method for determining the regional stress tensor using earthquake focal mechanism data; an application to the San Fernando earthquake sequence, J. Geophys. Res., 89, 9305-9320, 1984.

Hasegawa, A., S. Horiuchi, and N. Umino, Seismic structure of the north- 
eastern Japan convergent margin: A synthesis, J. Geophys. Res., 99, 22,295-22,311, 1994.

Hasegawa, A., K. Yoshida, and T. Okada, Nearly complete stress drop in the $2011 M_{\mathrm{w}} 9.0$ off the Pacific coast of Tohoku earthquake, Earth Planets Space, 63, 703-707, 2011.

Ide, S., A. Baltay, and G. C. Beroza, Shallow dynamic overshoot and energetic deep rupture in the $2011 \mathrm{Mw} 9.0$ Tohoku-oki earthquake, Science, 332, 1426-1429, 2011.

Japan Meteorological Agency, The Seismological and Volcanological Bulletin of Japan, Japan Meteorological Agency, Tokyo, 1998.

Koketsu, K., Y. Yokota, N. Nishimura, Y. Yagi, S. Miyazaki, K. Satake, Y. Fujii, H. Miyake, S. Sakai, Y. Yamanaka, and T. Okada, A unified source model for the 2011 Tohoku earthquake, Earth Planet. Sci. Lett., 310, 480-487, 2011.

Lay, T., J. C. Ammon, H. Kanamori, L. Xue, and J. M. Kim, Possible large near-trench slip during the $2011 \mathrm{Mw} 9.0$ off the Pacific coast of Tohoku Earthquake, Earth Planets Space, 63, 687-692, 2011.

Michael, A. J., Use of focal mechanisms to determine stress: a control study, J. Geophys. Res., 92, 357-368, 1987.

NIED Seismic Moment Tensor Catalog, www.fnet.bosai.go.jp.

Okada, Y., Internal deformation due to shear and tensile faults in a half space, Bull. Seismol. Soc. Am., 82, 1018-1040, 1992.

Otsubo, M., K. Sato, and A. Yamaji, Computerized identification of stress tensors determined from heterogeneous fault-slip data by combining the multiple inverse method and K-means clustering, J. Struct. Geol., 28, 991-997, 2006.

Otsubo, M., A. Yamaji, and A. Kubo, Determination of stresses from heterogeneous focal mechanism data: An adaptation of the multiple inverse method, Tectonophysics, 457, 150-160, 2008.

Sato, K. and A. Yamaji, Embedding stress difference in parameter space for stress tensor inversion, J. Struct. Geol., 28, 957-971, 2006.

Sato, M., T. Ishikawa, N. Ujihara, S. Yoshida, M. Fujita, M. Mochizuki, and A. Asada, Displacement Above the Hypocenter of the 2011 Tohoku-oki Earthquake, Science, 332, 1395; published online, 19 May (10.1126/science.1207401), 2011.

Suzuki, W., S. Aoi, H. Sekiguchi, and T. Kumagai, Rupture process of the 2011 Tohoku-Oki mega-thrust earthquake (M9.0) inverted from strong-motion data, Geophys. Res. Lett., 38, L00G16, doi:10.1029/2011GL049136, 2011.

Tsuji, T., T. Kanamatsu, K. Kawamura, K. Arai, K. Fujikura, Y. Ito, J. Ashi, M. Kinoshita, and T. Matsuoka, Fault system and dynamic seafloor deformation in the 2011 Tohoku earthquake, AGU fall meeting 2011, U41D-02, 2011.

Wallace, R. E., Geometry of shearing stress and relationship to faulting, $J$. Geol., 59, 111-130, 1951.

Wessel, P. and W. H. F. Smith, New version of the Generic Mapping Tools released, Eos Trans. AGU, 76, 329, 1995.

Yagi, Y. and Y. Fukahata, Rupture process of the 2011 Tohoku-oki earthquake and absolute elastic strain release, Geophys. Res. Lett., 38, L19307, doi:10.1029/2011GL048701, 2011.

Yamaji, A., The multiple inverse method: a new technique to separate stresses from heterogeneous fault-slip data, J. Struct. Geol., 22, 441452, 2000.

Yamaji, A. and K. Sato, Distances for the solutions of stresss tensor inversion in relation to misfit angle that accompany the solutions, Geophys. J. Int., 167, 913-942, 2006.

K. Chiba (e-mail: chiba@rcep.dpri.kyoto-u.ac.jp), Y. Iio, and Y. Fukahata 